\title{
Mesial cortical lesions and fear behavior in the wild rat
}

\author{
IVAN DIVAC and JESPER MOGENSEN \\ Institute of Neurophysiology, University of Copenhagen, Copenhagen, Denmark \\ and \\ ROBERT J. BLANCHARD and D. CAROLINE BLANCHARD \\ University of Hawaii, Honolulu, Hawaii
}

\begin{abstract}
Defensive behaviors of wild Rattus rattus were examined following lesions of anterior or posterior mesial cortex or control lesions in lateral cortical areas. The experimental lesions did not reduce flight, fear-based biting, or reactivity to contact or handling in these wild rats. The high levels of fear-related behaviors seen before surgery continued for all groups. Damage to the mesial cortex, which involves equivalents to the human prefrontal cortex, thus produced no indication of reductions in a variety of fear-related behaviors.
\end{abstract}

In one of the most influential experiments in neurobiology to date, Fulton and Jacobsen (1935) found an indication of decreased reaction to frustration in one of two chimpanzees with presumably identical lesions of the frontal lobes. This experiment triggered not only experiments on relations of the frontal lobes and emotions, but also a neurosurgical discipline presently known as "psychosurgery" (Freeman \& Watts, 1942; Moniz, 1936). Today, "the most appropriate candidates for psychosurgery are patients described as suffering from very intense and persistent emotional responses" (Valenstein, 1980b, p. 89). The mesial frontal cortex is a frequent target of neurosurgeons for relief from these symptoms (Valenstein, 1980a).

The role of the prefrontal cortex in "emotionality" is controversial: some experiments suggest such an involvement (Butter \& Snyder, 1972; Kolb, 1974; Markowska \& Lukaszewska, 1980), whereas others do not (e.g., Ur$\sin \&$ Divac, 1975). This controversy, which may be explained by differences in the studied species, the ablated cortical area, and the applied tests (Ursin \& Divac, 1975) is not found when other properties of the prefrontal cortex are considered. Thus, in all studied species, the prefrontal area, defined as the cortical target of the thalamic mediodorsal nucleus, was found to receive a strong dopaminergic innervation (e.g., Divac, Bjorklund, Lindvall, \& Passingham, 1978) and to mediate delayed response-type behavior (e.g., Wikmark, Divac, \& Weiss, 1973).

Relevance for psychosurgery requires detailed knowledge of the consequences of prefrontal lesions on var-

This work was supported by a grant from the Research Council of the University of Hawaii. The authors wish to thank Larry Pank and Dave Fellows of the U.S. Department of Interior, Wildlife Control Station at Hilo, Hawaii, for their assistance in the trapping of the wild rats. Reprint requests should be addressed to: R. J. Blanchard, 2430 Campus Road, Honolulu, HI 96822. ious aspects of emotional behavior. In the present study, we used wild trapped rats (Rattus rattus), which show more complete species-specific emotional behavior than do laboratory strains (Takahashi \& R. J. Blanchard, 1982). In our animals, either the anterior or posterior mesial cortex was ablated. This part of the rat cortex has been considered to be especially involved in speciesspecific behaviors (Thomas, Hostetter, \& Barker, 1968) and its rostral half in some aspects of emotional behavior (Kolb, 1974; Markowska, \& Lukaszewska, 1980). Anatomically, the rat anterior mesial cortex contains equivalents of the frontal eye field, the anterior limbic cortex, and both the medial and dorsolateral prefrontal cortex of the monkey (and presumably human) brain (see, e.g., Divac, Kosmal, Bjorklund, \& Lindvall, 1978).

\section{METHODS AND PROCEDURES}

\section{Surgery}

The lesions were made in rats anesthetized with pentobarbital by gentle subpial aspiration under control of an operation microscope. The intended border between the anteromedial and posteromedial lesions was at bregma.

\section{Histology}

Following the last behavioral procedure, all experimental animals were sacrificed with an overdose of sodium pentobarbital and administered a cardiac perfusion with $0.9 \%$ saline followed by $10 \%$ Formalin-saline solution. Brains were extracted, left in $30 \%$ sucroseformation, and cut on a freezing microtome at $40 \mu$. Each 5 th section was mounted and stained with cresyl violet.

\section{Behavioral Procedures}

Tests of reactivity to nonpainful stimuli were conducted 3 days before surgery and 4 and 13 days postoperatively. The following measures were taken.

Runway. All subjects were individually tested in a $10 \times 1.5 \mathrm{~m}$ runway that was partitioned by an 8.5 -m-long free-standing wall, with a $0.75-\mathrm{m}$ 'space on all sides and at the ends, which were rounded 
to produce a constant runway width. The runway was marked at $1-\mathrm{m}$ intervals.

The subjects were placed individually in the runway and monitored during a 5-min period for line crossings and circling or other motor dysfunctions. At the end of the 5-min period, the experimenter entered the runway and approached the subject $(0.5 \mathrm{~m} / \mathrm{sec})$, stopping when the subject moved more than $0.5 \mathrm{~m}$ in response to the approach. The initial distance to elicit flight and the escape distance travelled by the subject were recorded. The experimenter made five approaches, with a $30-\mathrm{sec}$ interval between approaches. The experimenter then approached the subject at a rate of $1.0 \mathrm{~m} / \mathrm{sec}$ and continued the approach until the subject moved $20 \mathrm{~m}$ or the subject was contacted three times in succession. The distance covered before one of these two events occurred was the chase distance.

The subjects were then placed individually in an open-top aluminum barrel, $50 \mathrm{~cm}$ in diameter and $120 \mathrm{~cm}$ high, and exposed to the following stimuli.

Dorsal contact. Subjects were tapped lightly on the back with a 8-mm-diam wooden dowel, $50 \mathrm{~cm}$ in length. A standard tapping procedure was used in which the end of the dowel was held $2 \mathrm{~cm}$ above the animal. The dowel was tapped quickly and lightly on the midback. Each trial consisted of three taps, and the subjects' responses were scored as " 1 " for startle 1 -a flinch reaction of the tapped surface only; " 2 " for startle 2-a flinch of the entire body; " 3 " for jump 1-rapid movement in which two of the subject's paws left the floor; " 4 "' for jump 2-a rapid movement in which all four paws left the floor; and " 5 " for jump 3-a rapid movement in which the subject jumped $10 \mathrm{~cm}$ or more. A sum for these responses was calculated over three trials.

Vibrissae stimulation. Subjects' vibrissae were stimulated with a circular brush, $2.5 \mathrm{~cm}$ in diameter, affixed perpendicularly to a 1-m-long wooden dowel. On each stroke, the brush was drawn upward, making extensive contact with the vibrissae. The number of strokes needed to elicit a boxing posture were recorded, with a maximum of five strokes per trial. The duration of the boxing posture was also recorded.

Anesthetized intruder. Subjects were presented with an anesthetized rat as a target, and measures of boxing, biting, vocalization, and jump attacks were taken. The target was held midventrally at ground level and moved head first toward the subject at a rate of $5 \mathrm{~cm} / \mathrm{sec}$, with three presentations per trial.

Pickup. Subjects were approached with a gloved hand at ground level and an attempt to pick up the subject was made by moving the hand under the subject's body. Measured responses included vocalization, biting, and success of the pickup. These three measures were summed to produce a defensive rating scale with " 0 ", representing lack of defensiveness and " 3 " representing maximal defensiveness.

\section{RESULTS}

\section{Histology}

The ablations in the three groups overlapped only slightly with one another. The anteromedial lesions damaged the target of the paralamellar and lateral segments of the mediodorsal nucleus of the thalamus (Divac, Bjorklund et al., 1978). This area appears to correspond to the frontal eye field, a part of the dorsolateral prefrontal area, and the anterior cingulate area of the monkey frontal cortex. These lesions were smaller than usual (see, e.g., Wikmark et al., 1973): they intentionally avoided the ventromedial cortex which probably belongs to the orbital prefrontal area (Divac, Kosmal et al., 1978). The posteromedial lesions damaged the retrosplenial field. The dorsolateral ablations invaded the premotor and motor

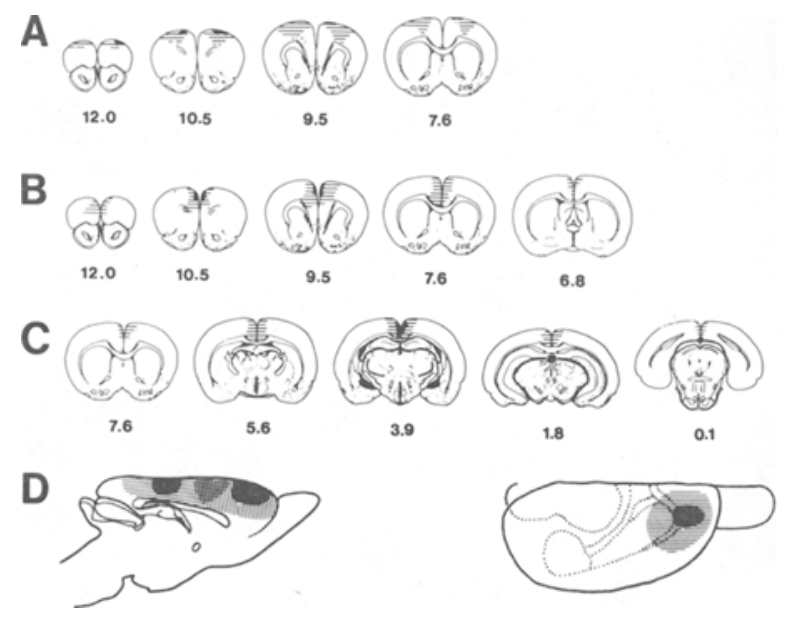

Figure 1. Minimal (black) and maximal (striped) areas of extent for anterior and posterior mesial lesions and for control (lateral) lesions. Series A (control), B (anterior), and C (posterior) give coronal sections; D presents a midsaggital section showing the anterior and posterior mesial lesions and a dorsal view of the control lesions.

areas (Hall \& Lindholm, 1974). The lesions are illustrated in Figure 1, which emphasizes the extremes; a "typical" lesion is somewhere between the black and striped area in Figure 1.

\section{Behavior}

All tests made 3 days preceding surgery produced essentially identical results for animals in the experimental and control groups. All subjects avoided the experimenter, ran considerable distances when chased, showed great reactivity to dorsal contact, bit an anesthetized conspecific, and squealed, bit, and struggled during the attempted pickup. These results, as well as postoperative tests for the three groups, are presented in Table 1.

When these measures were taken again 4 and 13 days after surgery, neither the control (lateral cortical) nor either of the two experimental groups showed any substantial alteration of fear-related behaviors. Although scores on some measures (e.g., percent avoidance) were maximal prior to surgery, and thus could show no increase, other tests (e.g., avoidance distance, reactions to dorsal contact, number of bites) could have varied in either direction. However, the data obtained suggest that these lesions do not substantively alter a wide range of fearbased, species-typical behaviors.

Statistical analysis indicated that activity $[\mathrm{F}(2,20)=$ 1.36], avoidance distance $[F(2,20)=1.34]$, chase distance $[F(2,20)=1.36]$, reaction to dorsal contact $[F(2,20)$ $=1.77]$, number of bites on the anesthetized intruder $F(2,20)=2.7]$, and ratings of defensiveness to pickup $[\mathrm{F}(2,20)=1.33]$ did not reach an acceptable level of statistical significance. There are, in fact, no indications of differences between groups on any of the dependent measures in the present study. The present results thus indicate an extremely consistent lack of change in fear 
Table 1

Mean Reactions of Cortically Damaged Wild Rats, Before and After Surgery

\begin{tabular}{|c|c|c|c|c|c|c|c|c|c|c|}
\hline & & \multicolumn{3}{|c|}{ Anterior Cortex } & \multicolumn{3}{|c|}{ Posterior Cortex } & \multicolumn{3}{|c|}{ Lateral Cortex } \\
\hline & & Pre & Post 4 & Post 13 & Pre & Post 4 & Post 13 & Pre & Post 4 & Post 13 \\
\hline Avoidance Distance & $\begin{array}{l}\text { Mean } \\
\text { SE }\end{array}$ & $\begin{array}{l}2.35 \\
0.31\end{array}$ & $\begin{array}{l}3.75 \\
0.22\end{array}$ & $\begin{array}{l}4.05 \\
0.18\end{array}$ & $\begin{array}{l}2.07 \\
0.32\end{array}$ & $\begin{array}{l}2.30 \\
0.38\end{array}$ & $\begin{array}{l}3.07 \\
0.27\end{array}$ & $\begin{array}{l}2.37 \\
0.49\end{array}$ & $\begin{array}{l}2.82 \\
0.48\end{array}$ & $\begin{array}{l}3.57 \\
0.38\end{array}$ \\
\hline Chase Distance & $\begin{array}{l}\text { Mean } \\
\text { SE }\end{array}$ & $\begin{array}{r}19.25 \\
0.53\end{array}$ & $\begin{array}{r}20.00 \\
0.00\end{array}$ & $\begin{array}{r}20.00 \\
0.00\end{array}$ & $\begin{array}{r}19.22 \\
0.51\end{array}$ & $\begin{array}{r}20.00 \\
0.00\end{array}$ & $\begin{array}{r}20.00 \\
0.00\end{array}$ & $\begin{array}{r}17.83 \\
1.64\end{array}$ & $\begin{array}{r}20.00 \\
0.00\end{array}$ & $\begin{array}{r}20.00 \\
0.00\end{array}$ \\
\hline Reaction to Dorsal Contact & $\begin{array}{l}\text { Mean } \\
\text { SE }\end{array}$ & $\begin{array}{r}11.25 \\
1.37\end{array}$ & $\begin{array}{r}14.00 \\
0.47\end{array}$ & $\begin{array}{r}14.61 \\
0.38\end{array}$ & $\begin{array}{r}13.22 \\
0.95\end{array}$ & $\begin{array}{r}12.44 \\
1.13\end{array}$ & $\begin{array}{r}12.67 \\
1.30\end{array}$ & $\begin{array}{r}13.00 \\
1.29\end{array}$ & $\begin{array}{r}12.82 \\
1.33\end{array}$ & $\begin{array}{r}13.00 \\
2.00\end{array}$ \\
\hline \multicolumn{11}{|c|}{ Reaction To Anesthetized Intruder } \\
\hline Percent Biting & & 95.83 & 87.50 & 87.50 & 74.07 & 77.77 & 66.77 & 72.20 & 66.66 & 66.67 \\
\hline Number of Bites & $\begin{array}{l}\text { Mean } \\
\text { SE }\end{array}$ & $\begin{array}{l}2.86 \\
0.11\end{array}$ & $\begin{array}{l}5.13 \\
1.03\end{array}$ & $\begin{array}{l}6.25 \\
1.13\end{array}$ & $\begin{array}{l}2.21 \\
0.35\end{array}$ & $\begin{array}{l}3.66 \\
0.93\end{array}$ & $\begin{array}{l}2.78 \\
0.97\end{array}$ & $\begin{array}{l}2.17 \\
0.53\end{array}$ & $\begin{array}{l}3.50 \\
1.37\end{array}$ & $\begin{array}{l}4.67 \\
1.73\end{array}$ \\
\hline Rated Defense to Pickup & $\begin{array}{l}\text { Mean } \\
\text { SE }\end{array}$ & $\begin{array}{l}2.86 \\
0.08\end{array}$ & $\begin{array}{l}2.81 \\
0.12\end{array}$ & $\begin{array}{l}2.86 \\
0.07\end{array}$ & $\begin{array}{l}2.93 \\
0.05\end{array}$ & $\begin{array}{l}2.71 \\
0.11\end{array}$ & $\begin{array}{l}2.60 \\
0.17\end{array}$ & $\begin{array}{l}2.83 \\
0.17\end{array}$ & $\begin{array}{l}2.42 \\
0.30\end{array}$ & $\begin{array}{l}2.50 \\
0.32\end{array}$ \\
\hline
\end{tabular}

and defensive behaviors of wild rats following aspiration of the anterior or posterior medial cortical regions.

\section{DISCUSSION}

Anteromedial lesions of approximately the same size as those of the present study have been shown to impair a number of behaviors, such as spatial reversals (Divac, 1971), delayed alternation (Eichenbaum, Clegg, \& Feeley, 1983), open-field activity (Brennan, 1979), and responding to reinforcement omission (McDonough \& Manning, 1979). Thus, our negative results cannot be attributed simply to the small size of the lesions.

Moreover, the procedures used in the present study have previously been used to demonstrate clear taming effects in wild rats after amygdaloid lesions (Kemble, D. C. Blanchard, R. J. Blanchard, \& Takushi, 1984), basal ganglia (D. C. Blanchard, R. J. Blanchard, Lee, \& Williams, 1981), and central gray (D. C. Blanchard, Williams, Lee, \& R. J. Blanchard, 1981) damage. These tests do not involve painful stimulation, but instead measure natural defensive and fear-related behaviors of wild and laboratory rats to biologically meaningful threat stimuli.

The present results provide no evidence for any reduction in such behaviors following these cortical lesions: Wild rats confronted by a variety of extremely threatening stimuli showed normal, intense, patterns of fear. It might be noted that even those subjects with the largest areas of damage showed no evidence of a decrease in defensiveness.

The present work thus provides full support of the work of Ursin and Divac (1975), who also failed to show an effect of lesions on the prefrontal cortex in the feral cat. Although the present study presents strong evidence that these "prefrontal" lesions do not produce a decrease in species-typical defensive behaviors, it should be noted that the wild rat is not an appropriate model for determining the potentiation of defense; the defensiveness of these animals is so great that it limits the possibility of a detectable increase in fearfulness. Thus, the present results are best interpreted as evidence against a view that prefron- tal cortex damage reduces defense. This is, nevertheless, a significant finding in terms of previous suggestions that lesions in this area do reduce species-typical defensive behaviors.

\section{REFERENCES}

Blanchard, D. C., Blanchard, R. J., Lee, E. M. C., \& Williams, G. (1981). Taming in the wild Norway rat following lesions in the basal ganglia. Physiology \& Behavior, 27, 995-1000.

Blanchard, D. C., Williams, G., Lee, E. M. C., \& Blanchard, R. J. (1981). Taming of wild Rattus norvegicus by lesions of the mesencephalic central gray. Physiological Psychology, 9, 157-163.

BrenNan, J. F. (1979). Prefrontal lesions effects on suppression of openfield activity in young and adult rats. Physiological Psychology, 7, 333-338.

BUTTER, C. M., \& SNYDER, D. R. (1972). Alterations in aversive and aggressive behaviors following orbital lesions in rhesus monkeys. Acta Neurobiologiae Experimentalis (Warsaw), 32, 525-565.

Divac, I. (1971). Frontal lobe system and spatial reversal in the rat. Neuropsychologia, 9, 175-183.

Divac, I., Buorklund, A. L., Lindvall, O., Passingham, R. E. (1978). Converging projections from the mediodorsal thalamic nucleus and mesencephalic dopaminergic neurons to the neocortex in three species. Journal of Comparative Neurology, 180, 59-72.

Divac, I., Kosmal, A., Bjorklund, A., \& Lindvall, O. (1978). Subcortical projections to the prefrontal cortex in the rat as revealed by the horseradish peroxidase technique. Neuroscience, 3, 785-796.

Eichendaum, H., Clegg, R. A., \& Feeley, A. (1983). Reexamination of functional subdivisions of the rodent prefrontal cortex. Experimental Neurology, 79, 434-451.

Freeman, W., \& WatTs, J. W. (1942). Psychosurgery. Springfield IL: Thomas.

Fulton, J. F., \& JACOBSEN, C. F. (1935). The functions of the frontal lobes, a comparative study in monkeys, chimpanzees and man. $A b$ stracts of the 2nd International Neurological Congress, London, 70-71.

HALL, R. D., \& LiNDhOLM, E. P. (1974). Organization of motor and somatosensory neocortex in the albino rat. Brain Research, 66, 23-38.

Kemble, E. D., Blanchard, D. C., Blanchard, R. J., \& TaKushi, R. (1984). Taming in wild rats following medial amygdaloid lesions. Physiology \& Behavior, 32, 131-134.

KoLB, B. (1974). Social behavior of rats with chronic prefrontal lesions. Journal of Comparative Physiology and Psychology, 87, 466-474. MARKOWSKA, A., \& LUKASZEWSKA, I. (1980). Emotional reactivity after frontomedial cortical, neostriatal or hippocampal lesions in rats. Acto Neurobiologiae Experimentalis (Warsaw), 40, 881-893.

McDonough, J. H., JR., \& Manning, F. J. (1979). The effects of lesions in amygdala or dorsomedial frontal cortex on reinforcement omission and noncontingent reinforcement in rats. Physiological Psychology, 7, 167-172. 
Moniz, E. (1936). Tentatives operatoires dans le traitement de certaines psychoses. Paris: Masson \& Cie.

Takahashi, L. K., \& Blanchard, R. J. (1982). Attack and defense in wild and laboratory norway rats. Behavioural Processes, 7, 46-62.

Thomas, G. J., Hostetter, G., \& Barker, D. J. (1968). Behavioral functions of the limbic system. In E. Stellar \& J. M. Sprague (Eds.), Progress in physiological psychology (Vol. 2, pp. 229-311). New York: Academic Press.

UrSIN, H., \& DIVAC, I. (1975). Emotional behavior in feral cats with ablations of the prefrontal cortex and subsequent lesions in amygdala. Journal of Comparative Physiology and Psychology, 88, 36-39.

VALENSTEIN, E. S. (1980a). Rationale and surgical procedures. In E.
S. Valenstein (Ed.), The psychosurgery debate (pp. 55-75). San Francisco: Freeman.

VAlenstein, E. S. (1980b). Who receives psychosurgery. In E. S. Valenstein (Ed.), The psychosurgery debate (pp. 89-107). San Francisco: Freeman

Wikmark, R. G. E., Divac, I., \& WEISs, R. (1973). Retention of spatial delayed alternation in rats with lesions in the frontal lobes. Implications for a comparative neuropsychology of the prefrontal system. Brain, Behavior and Evolution, 8, 329-339.

(Manuscript received May 28, 1984; revision accepted for publication November 11, 1984.) 